\title{
Presumed interference colours at the level of the human anterior lens capsule
}

\begin{abstract}
Purpose To assess the incidence and related factors of the presumed interference colour phenomenon at the anterior lens capsule. Methods In 274 eyes of 137 normal subjects, ranging in age from 4 to 83 years old

(50.1 \pm 24.9 years, mean \pm standard deviation), the anterior lens capsule was observed with slit-lamp microscopy under specular conditions to assess the presence and degree of presumed interference colours.

Results The colouring phenomenon, which was thought to be relevant to the interference phenomenon induced at the level of the anterior lens capsule, was found in $67.5 \%$ of eyes. Typically, there was a colour spectrum with a greenish tint in the central area and a reddish tint at the periphery, which coincided with the area of capsular shagreen. Multiple regression analysis revealed a signigificant positive correlation between the degree of the interference colour phenomenon and the age of the subjects $\left(r=0.45, p<0.0001, R^{2}=0.713\right)$. Conclusion Presumed interference colours are frequently seen at the human anterior lens capsule. Interference colours and capsular shagreen seem to reflect age-related changes in the lens.
\end{abstract}

Key words Anterior lens capsule, Interference colour, Shagreen, Specular reflection

S. Amano

Department of

Ophthalmology

University of Tokyo School

of Medicine

Tokyo, Japan

Tetsuro Oshika, MD

Department of

Ophthalmology

University of Tokyo School of Medicine

7-3-1 Hongo, Bunkyo-ku

Tokyo 113-8655, Japan

Tel: +8133815 5411

Fax: +81338170798

e-mail: oshika-tky@umin.ac.jp

Received: 5 September 2000

Accepted in revised form:

10 November 2000
In the 1920s, $\operatorname{Vogt}^{1}$ depicted the specular features of the human lens in vivo, such as capsular shagreen, in his textbook and atlas of slit-lamp microscopy of the living eye. Capsular shagreen is a coarse, beaten-metal-like reflex seen over the anterior capsule. ${ }^{2-5}$ Recently, we noticed a colouring phenomenon of the anterior capsule in conjunction with the shagreen, which was observable by slit-lamp microscopy under specular conditions. Although this phenomenon resembled the appearance of interference colour found on antireflection-coated lenses, its occurrence has never been described in the literature. In the current study, we assessed the

YASUYUKI NAKASHIMA, FUMIAKI YOSHITOMI, SHIRO AMANO, TETSURO OSHIKA

incidence and related factors of the presumed interference colour phenomenon in normal human eyes.

\section{Subjects and methods}

Two hundred and seventy-four eyes of 137 subjects were included in the study. Their age averaged $50.1 \pm 24.9$ years old (mean \pm standard deviation), ranging from 4 to 83 years old. None of the eyes had any ocular diseases except for mild refractive error and age-related cataract. Eyes were not included if they had any history of previous ocular surgery.

After the pupil was dilated, the anterior lens capsule was observed with a slit-lamp microscope at specular reflection. The degree of presumed interference colours was subjectively graded from 0 to 3 according to the scale shown in Fig. 1. Changing the angle of view had little effect on the degree of the colouring phenomenon. Grading was done at a viewing angle of approximately $20^{\circ}-40^{\circ}$ from the optical axis.

The degree of nucleus sclerosis was classified from 0 to 5 . The presence of pseudoexfoliation was recorded.

Multiple regression analysis was performed to investigate the correlation between several variables and the degree of presumed interference colours. Variables tested were age, gender, degree of nucleus sclerosis and presence of pseudoexfoliation.

\section{Results}

The presumed interference colours were found mainly in subjects older than 40 years and were always seen with capsular shagreen. Typically. there was some colour spectrum, with a greenish colour seen in the central area and a reddish colour at the periphery. Eighty-nine eyes (32.5\%) showed grade 0 colouring, 33 eyes $(12.0 \%)$ grade 1,83 eyes $(30.3 \%)$ grade 2 , and 69 eyes $(25.2 \%)$ grade 3 .

Multiple regression analysis revealed a significant positive correlation between the degree of presumed interference colours and the age of the subjects (Fig. 2). The remaining 
Table 1. Results of multiple regression analysis to test the correlation between several variables and presumed interference colours at the anterior lens capsule

\begin{tabular}{lcc}
\hline Variables & $\begin{array}{c}\text { Partial regression } \\
\text { coefficient }\end{array}$ & $p$ value \\
\hline Age (years) & 0.045 & $<0.0001$ \\
Gender & 0.099 & 0.251 \\
Nucleus sclerosis & -0.101 & 0.213 \\
Presence of pseudoexfoliation & -0.157 & 0.438 \\
Constant & -0.818 & \\
\hline
\end{tabular}

Adjusted $R^{2}=0.713$.

variables did not show statistically significant contributions (Table 1). The degree of presumed interference colours was predicted by $-0.582+0.042 \times$ age, with an adjusted $R^{2}$ value of 0.713 .

\section{Discussion}

A green ring in the peripheral anterior lens capsule has been reported in 5 members of a family. ${ }^{6}$ The aetiology remained unclear and no other reports have been available on this phenomenon. The ring was monochromatic, independent of the specular condition and more intense in younger subjects. The colouring phenomenon presented herein differs from the green ring phenomenon in that there was a colour spectrum from green to red, seen only under specular conditions, and more intense in older subjects.

The colouring phenomenon at the anterior capsule closely resembled the interference colour seen on antireflection-coated lenses. Moreover, it appeared as a colour spectrum from green to red, and was observable only at specular reflection. Thus, this phenomenon was most likely caused by the interference of light. When the interference of light is induced by a thin film (layer), its thickness should be in the order of the wavelength of

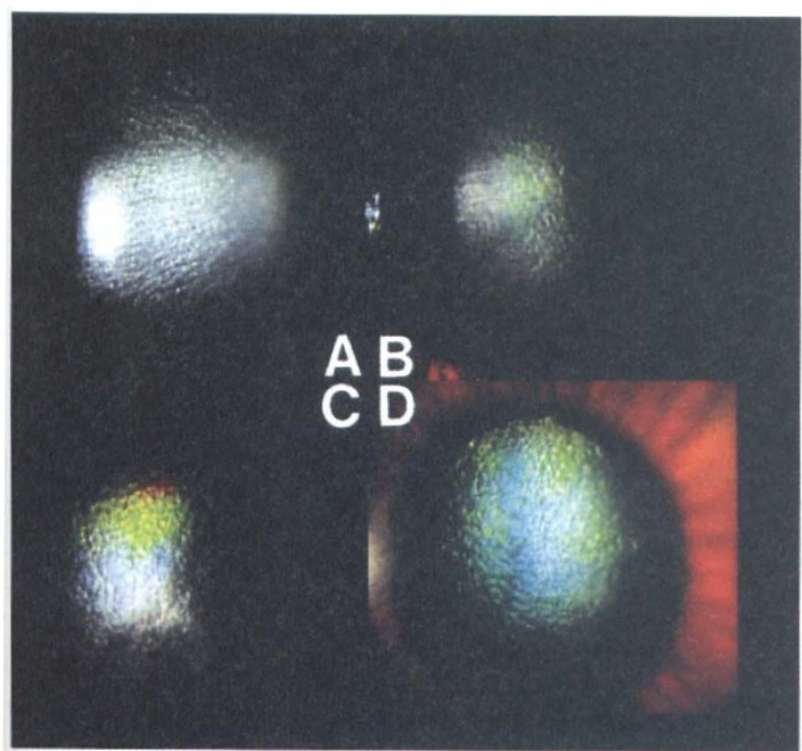

Fig. 1. Degree of presumed interference colours at the anterior lens capsule observed under specular conditions. (A) Grade 0: no detectable colouring. (B) Grade 1: slight colouring at the periphery. (C) Grade 2: moderate colouring at the periphery. (D) Grade 3: apparent colouring both in the centre and at the periphery.

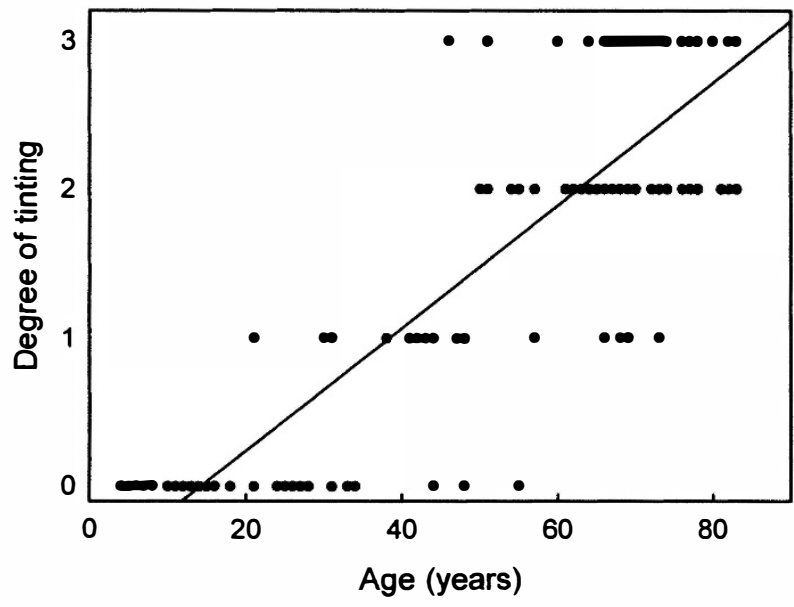

Fig. 2. Correlation between age and degree of presumed interference colours.

visible light (380-810 nm). The thickness of the anterior capsule, however, is approximately $10-30 \mu \mathrm{m},{ }^{7-9}$ which is far beyond the range of thickness capable of causing interference. Thus, the source of interference cannot be the surfaces of the anterior capsule.

In the current study, the presumed interference colours were consistently found with capsular shagreen. It has been reported that the shagreen pattern also shows age-related changes, i.e. the size of coarse patterns becomes irregular in aged lenses. ${ }^{4}$ The structural basis for the biomicroscopically visible shagreen is not yet understood. Since the capsule surface appears generally smooth by slit-lamp biomicroscopy, capsular shagreen is thought to represent optical variations within or adjacent to the lens capsule. ${ }^{10}$ Sasaki et al. ${ }^{4}$ postulated that shagreen patterns may reflect the lens epithelium and basement-membrane-like layer.

Although the lens capsule appears quite homogeneous at the light microscopic level, ${ }^{5}$ the presence of partial splitting of the anterior lens capsule has been reported. ${ }^{11,12}$ Moreover, electron microscopy revealed a structure consisting of up to 40 lamellae, each of which is about $40 \mathrm{~nm}$ thick. ${ }^{13}$ At higher resolution, fine fibrils are identified which are in the region of $2.5 \mathrm{~nm}$ in diameter. ${ }^{14}$ The lamellae run parallel to the capsular surface. There are suggestions that the lamellar structure becomes modified with age. ${ }^{7}$ These structures could be the source of interference of light as well as capsular shagreen. Another possibility is that some unknown structure or space beneath the capsule causes optical variations, leading to the observation of colouring and shagreen. In any case, it seems that presumed interference colour and shagreen phenomena reflect ageing changes in the microstructure of the lens.

\section{References}

1. Vogt A. The normal lens. In: Textbook and atlas of slit lamp microcopy of the living eye. Vol. II. Lens and zonules. Bonn: Wayenborgh, 1979:26-74.

2. Fine BS, Yanoff M. The lens. In: Ocular histology: a text and atlas. 2nd ed. Maryland: Harper \& Row, 1979:147-59. 
3. Bron AJ, Matsuda K. Specular microscopy of the human lens. Trans Ophthalmol Soc UK 1981;101:163-9.

4. Sasaki K, Kojima M, Hara T. In vivo observation of the crystalline lens capsule. Ophthalmic Res 1988;20:154-9.

5. Bron AJ, Tripathi RC, Tripathi BJ. The lens and zonules. In: Wolff's anatomy of the eye and orbit. 8th ed. London: Chapman \& Hall Medical, 1997:411-42.

6. Jaeger W. Green ring of the anterior lens capsule. In: Henkind P, editor. XXIV International Congress of Ophthalmology, vol 1. Philadelphia: JB Lippincott, 1983:63-5.

7. Seland JH. Ultrastructural changes in the normal human lens capsule from birth to old age. Acta Ophthalmol (Copenh) 1974;52:688-96.

8. Straatsma BR, Lightfoot DO, Barke RM, Horwitz J. Lens capsule and epithelium in age-related cataract. Am J Ophthalmol 1991;112:283-96.
9. Krag S, Olsen T, Andreassen TT. Biomechanical characteristics of the human anterior lens capsule in relation to age. Invest Ophthalmol Vis Sci 1997;38:357-63.

10. Tripathi RC, Tripathi BJ. Anatomy of the human eye, orbit, and adnexa. In: Davson H, editor. The eye. 3rd ed. London: Academic Press, 1984:1-268.

11. Braude LS, Edward DP. Partial splitting of the anterior lens capsule giving a 'double-ring' sign. Arch Ophthalmol 1995;113:705-6.

12. Wollensak G, Wollensak J. Double contour of the lens capsule edges after continuous curvilinear capsulorhexis. Graefes Arch Clin Exp Ophthalmol 1997;235:204-7.

13. Worgul BV. Lens. In: Duane TD, Jaeger EA, editors. Biomedical foundations of ophthalmology. Vol 1. Philadelphia: Harper \& Row, 1982:chap 15.

14. Fisher RF, Hayes BP. Thickness and volume constants and ultrastructural organization of basement membrane (lens capsule). J Physiol (Lond) 1979;293:229-45. 